\title{
Betulinic Acid-induced Mcl-1 Expression in Human Melanoma - Mode of Action and Functional Significance
}

\author{
Edgar Selzer, ${ }^{1,2,4}$ Christiane Thallinger, ${ }^{1,3}$ Christoph Hoeller, ${ }^{3}$ Philipp Oberkleiner, ${ }^{1}$ \\ Volker Wacheck, ${ }^{1}$ Hubert Pehamberger, ${ }^{3,4,5}$ and Burkhard Jansen ${ }^{1,3}$ \\ ${ }^{1}$ Department of Clinical Pharmacology, Section of Experimental Oncology and Molecular Pharmacology \\ ${ }^{2}$ Department of Radiotherapy and Radiobiology \\ ${ }^{3}$ Department of Dermatology, Division of General Dermatology \\ ${ }^{4}$ Center of Excellence for Clinical and Experimental Oncology (CLEXO) \\ ${ }^{5}$ Ludwig Boltzmann Institute for Clinical and Experimental Oncology, University Hospital Vienna, \\ Vienna, Austria
}

Accepted October 10, 2002

\begin{abstract}
Background: Currently there is no information on the regulation of expression and physiological role of the antiapoptotic protein $\mathrm{Mcl}-\mathrm{l}$ in cells of the melanocytic lineage. This study investigates the regulation and expression of Mcl-1 in human melanoma cells, which was recently found to be induced by betulinic acid, a compound with anti-melanoma and apoptosis-inducing potential.

Materials and Methods: Mcl-1 phosphorthioate antisense oligonucleotides were used to investigate the effect of downregulating the expression of Mcl-1. Regulation of Mcl-1 expression was analyzed with the specific PI3kinase inhibitors LY294002 and wortmannin and the inhibitor of MAP-kinase activation, PD98059. Western blot analysis was performed with anti ERK1/2, Mcl-1, Bak, Bcl-X and Bax antibodies. Activation status of PI-3 kinase and MAP-kinase pathways was investigated using phospho-Akt and phosphorylation-state independent Akt as well as phospho-MAP kinase, phospho-MEK and phospho-GSK-3 $\alpha / \beta$ antibodies.
\end{abstract}

Results: Upregulation of Mcl-1 in human melanoma cells by betulinic acid is mediated via a signal-transduction pathway that is inhibited by LY294002 and wortmannin. Betulinic acid-induced phosphorylation and activation of the Akt protein kinase was inhibited by LY294002. The inhibitor PD98059 reduced expression levels of Mcl-1 in melanoma cells and this effect was counteracted by betulinic acid. Downregulation of $\mathrm{Mcl}-1$ by antisense oligodeoxynucleotides in combination with betulinic treatment led to a synergistic effect regarding growth inhibition.

Conclusions: These results suggest that in human melanoma cells Mcl-1 is (i) of functional relevance for survival and (ii) subject to dual regulation by the MAPkinase pathway and a pathway involving protein kinase $\mathrm{B} / \mathrm{Akt}$, the latter of which is modulated in response to betulinic acid. This study provides an experimental foundation for future therapeutic strategies using anti-Mcl-1 antisense oligonucleotides in human melanoma.

\section{Introduction}

Mcl-1 is a member of the Bcl-2 family, the existence of which was described for the first time only recently in cells of the melanocytic lineage $(1,2)$. Subsequently, our group found that the expression of the anti-apoptotic protein Mcl-1 in human melanoma is induced rapidly by betulinic acid, a substance that induces apoptosis in a TP53 independent manner ( 1 , and references therein). These observations led to further investigation into the function and regulation of expression of Mcl-1 in human melanocytes or melanoma cells.

While little is known about the initial signal transduction pathways that are involved in the mech-

Address correspondence and reprint requests to: Edgar Selzer, Dept. of Clinical Pharmacology 18-20, 1090 Vienna, Austria, Phone: +43-1-40400-7672, fax: +43-1-40400-2666,

email: Edgar.Selzer@AKH-Wien.ac.at. anism of action of betulinic acid, activation of the apoptotic pathway by betulinic acid has been investigated in detail by other groups (3-8). Contrasting the lack of knowledge in melanocytes, the mechanisms of Mcl-1 expression are understood better in other systems, and especially well in the haematopoietic system. For example, Granulocyte-macrophage colony-stimulating factor (GM-CSF) induced upregulation of the anti-apoptotic protein Mcl-1 in hematopoietic cells (9) appears to be mediated by the phosphatidylinositol 3-kinase/Akt signaling pathway (10). In neutrophils, apoptosis can be modified via PI3-kinase as well as by MAPK-dependent pathways (11). PI3-K/Akt and MAPK pathway dependent regulation of $\mathrm{Mcl}-1$, and of apoptosis generally, has been described (12-18).

Thus the established data in other cellular systems, and our own initial observations regarding the effect of betulinic acid on Mcl-1 expression, led us to 
investigate in more detail the potential roles of the MEK/MAPK and PI-3K/Akt pathways in the regulation of Mcl-1 in response to betulinic acid and other substances in human melanoma. Further, we set out to determine if Mcl-1 carries survivalpromoting functions in melanoma, potentially contributing to the exceptional treatment-resistant phenotype of this malignancy.

\section{Materials and Methods}

Cell Lines and Culture

Fetal calf serum (heat inactivated) and Dulbecco's modified Eagle medium and other cell culture reagents were purchased from Gibco BRL (Grand Island, NY, USA). Medium and growth factors for normal human melanocytes were obtained from Clonetics Corporation (Remagen, Germany). Protease inhibitors were obtained from Boehringer Mannheim (Mannheim, Germany). ECL Western blotting reagents were obtained from Boehringer Mannheim. Betulinic acid was kindly provided by Dr. Reinhard Paschke (Biozentrum-Halle, Halle, Germany). The melanoma cell line 518A2 and the $\mathrm{N}$-ras transfectants (518-L1 (61-leu/L)) as well as the neomycin control transfectants (518-neo) were a kind gift of Dr. Peter Schrier, University of Leiden (Netherlands) and have been recently described (19). The human melanoma cell line M20 used in this study was generated from melanoma metastases and characterized in our laboratory (2). The spontaneously transformed cell line NMel-II was established from normal primary human neonatal melanocytes in this laboratory (1). The cell lines were maintained in Dulbecco's modified Eagle medium (4500 mg/l Glucose) supplemented with $10 \%$ fetal calf serum (Gibco BRL).

\section{Conditions for Cell Culture and Assays}

Cells were treated in exponential growth phase with betulinic acid at the concentrations indicated. The PI3-kinase inhibitor LY294002 and betulinic acid were reconstituted in DMSO as a stock solution (both at $5 \mathrm{mg} / \mathrm{ml}$ ) and stored until usage at $-80^{\circ} \mathrm{C}$. The inhibitor of MAP-kinase activation, PD98059 and the inhibitors of PI3-kinase, wortmannin and LY294002, were from Calbiochem (San Diego, CA, USA). Wortmannin, LY294002 and PD98059 were added $60 \mathrm{~min}$ before treatment of cells with betulinic acid to the culture medium. In brief, cells were maintained in standard medium, harvested and plated at equal and subconfluent densities in tissue culture dishes. The next day, medium was changed, and the day after medium change cells were exposed to the treatments with betulinic acid and/or the substances indicated with pre-warmed fresh medium. The control experiments were performed with DMSO added corresponding to the maximal concentration of DMSO added together with betulinic acid, PD98059, wortmannin and LY294002, respectively. DMSO control experiments using up to $0.4 \%$ DMSO final concentration in the culture medium indicated that this solvent had no significant effect on survival or on the experiments performed in our studies (data not shown). Survival was determined by counting cell numbers at the time points indicated.

\section{Western Blot Analysis and Immunodetection}

Cell extracts were prepared in lysis-buffer containing $0.14 \mathrm{M} \mathrm{NaCl}, 0.4 \mathrm{M}$ triethanolamine, $0.2 \% \mathrm{Na}-$ deoxycholate, $0.5 \%$ Nonidet P-40, supplemented with $1 \mathrm{mM}$ phenylmethylsulfonyl fluoride, $8.0 \mu \mathrm{g} / \mathrm{ml}$ aprotinin and $1 \mathrm{mM}$ orthovanadate. For phosphospecific immunoblots the lysis buffer contained $50 \mathrm{mM}$ Tris, $40 \mathrm{mM} \beta$-glycerophosphate, $100 \mathrm{mM}$ $\mathrm{NaCl}, 10 \mathrm{mM}$ EDTA, $10 \mathrm{mM} p$-nitrophenol phos-

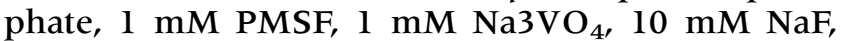
$1 \%$ Nonidet P-40, 0, $1 \%$ SDS, 250 units $/ \mathrm{ml}$ aprotinin and $40 \mu \mathrm{g} / \mathrm{ml}$ leupeptin. The amount of soluble protein was then quantified by means of a modified Bradford analysis (Bio-Rad, Richmond, CA, USA). Total lysates (20 $\mu \mathrm{g}$ per lane) were separated by SDS polyacrylamide gel electrophoresis and blotted onto nitrocellulose membranes. Bound antigen was visualized with the enhanced chemiluminescence detection system (ECL) from Boehringer Mannheim. These procedures were performed in principle as suggested by the manufacturers. Anti non-phosphorylated ERK1/2 (K23), Mcl-1 (S-19), Bak (G23), Bcl-x (S-18) and Bax (P-19) antibodies were obtained from Santa Cruz Biotechnology (Santa Cruz, CA, USA). PhosphoAkt and phosphorylation-state independent Akt as well as phospho-MAP kinase, phospho-MEK and phospho-GSK- $3 \alpha / \beta$ antibodies were obtained from Cell Signaling Technology (Beverly, MA, USA, formerly New England Biolabs).

\section{RNase Protection Assay}

For RNase protection analysis, the Multi-Probe Ribonuclease Protection Assay System from Pharmingen (SanDiego, CA) for human apoptosis related genes was used according to the manufacturers protocol. DNA templates corresponding to the probes were used for T7 RNA polymerase-directed synthesis of $\left[\alpha^{32} \mathrm{P}\right]$-labelled anti-sense RNA probes that were subsequently hybridized with total RNA. Free probe and other single-stranded RNA molecules were then digested with RNase and the remaining RNase-protected probes were purified, resolved on a denaturing polyacrylamide gel according to their size and imaged by autoradiography. The identity of the protected fragments in the RNA population of the treated and control cells was established by generating a standard curve after measuring the migration distance for the unprotected probes provided by the supplier.

\section{Mcl-1 Antisense Oligodeoxynucleotides and Transfection}

2`-O-Methoxyethyl/2`-deoxynucleotide chimeric phosphorthioate antisense oligo-deoxynucleotides were 
kindly provided free of charge by ISIS Pharmaceuticals (Carlsbad, CA). The sequence of Mcl-1 antisense oligonucleotide (ISIS 20408) was 5'-TTGGCTTTGTGTCCTTGGCG-3`. The control antisense oligonucleotide contained four mismatches at the positions indicated (bold and underlined): 5'TTGGCCTGGTTTCTTTGGCG-3`. For transfection, 300,000 cells were seeded in a $75 \mathrm{~cm}^{2}$ plate $24 \mathrm{~h}$ prior to the oligonucleotide treatment. Oligodeoxynucleotides were delivered to the cells in the form of complexes with the transfection reagent Lipofectin (Gibco BRL) in principle as described by the supplier. In short, following complex formation with the transfection reagent, oligodeoxynucleotides were diluted to the desired concentration in antibiotic free medium without serum and cells were incubated with this mixture for $4 \mathrm{~h}$. After washing once with medium alone, cells were further cultured in complete medium containing serum and growth factors and/or inhibitors, as indicated below.

\section{Akt Kinase Assay}

For nonradioactive measurement of Akt kinase activity, a Kinase assay kit was obtained from Cell Signaling Technology and used as suggested by the manufacturer. In short, cells were treated or untreated with the indicated substances. After addition of cell lysis buffer [20 mM Tris ( $\mathrm{pH} 7.5)$, $150 \mathrm{mM} \mathrm{NaCl}$, 1 mM EDTA, 1 mM EGTA, 1\% Triton, $2.5 \mathrm{mM}$ sodium pyrophosphate, $1 \mathrm{mM} \beta$-Glycerolphosphate, $1 \mathrm{mM} \mathrm{Na} \mathrm{VO}_{4}, 1 \mu \mathrm{g} / \mathrm{ml}$ Leupeptin, 1 mM PMSF], a selective immunoprecipitation of Akt using immobilized Akt antibody was performed. After immunoprecipitation, pellets were incubated for $30 \mathrm{~min}$ in kinase buffer [ $25 \mathrm{mM}$ Tris ( $\mathrm{pH} 7.5)$, $2 \mathrm{mM}$ DTT, $5 \mathrm{mM} \beta$-Glycerolphosphate, $0.1 \mathrm{mM}$ $\mathrm{Na}_{3} \mathrm{VO}_{4}, 10 \mathrm{mM} \mathrm{MgCl} 2,200 \mu \mathrm{M}$ ATP] containing glycogen synthetase kinase-3 (GSK-3) fusion protein that serves as a substrate for phosphorylation by Akt. Phosphorylation of GSK-3 is then analyzed by Western blotting using a phospho-GSK- $3 \alpha / \beta$ antibody.

\section{Statistics}

Student's t-test was used for calculating significance levels. $\mathbf{P}$ values of less than 0.05 were considered to be of statistical significance.

\section{Results \\ Analysis of the Expression of Mcl-1 in Melanoma Cells after Treatment with Betulinic Acid Alone and \\ in Combination with LY294002}

We recently investigated the expression of Bcl-2 homologues after treatment with betulinic acid in melanocytes and found that betulinic acid maximally induced the expression of the anti-apoptotic protein Mcl-1 in melanoma cells within 6 to 8 hours. The response of Mcl-1 continued for up to 48 hours and the data obtained by densitometric scanning analysis of Western blots of Mcl-1 expression measured in five different transformed melanocytic cell lines after treatment with betulinic acid showed an up to 3-fold induction of Mcl-1 (1). To the best of our knowledge, no information about the signal transduction pathways controlling Mcl-1 expression in normal human melanocytes or in melanoma cell lines is currently available. We addressed this issue here and based on what is known about the regulation of Mcl-1 expression from other systems, we first studied the PI3-kinase pathway using the welldescribed PI3-kinase specific inhibitors LY294002 and wortmannin.

Betulinic acid preferentially induces the Expression of Mcl-1, but not of the other Bcl-2 Family Members in a LY294002/Wortmannin-sensitive Manner

(Fig.1A) Addition of betulinic acid rapidly and strongly induces the expression of Mcl- 1 in human melanoma cells. In this experiment, induction is after 8 hours. Addition of LY294002 one hour before treatment with betulinic acid at least partially antagonized this effect. The analysis of two selected Bcl-2 family members Bax and Bak in parallel indicates that Mcl-1 is affected whereas the expression
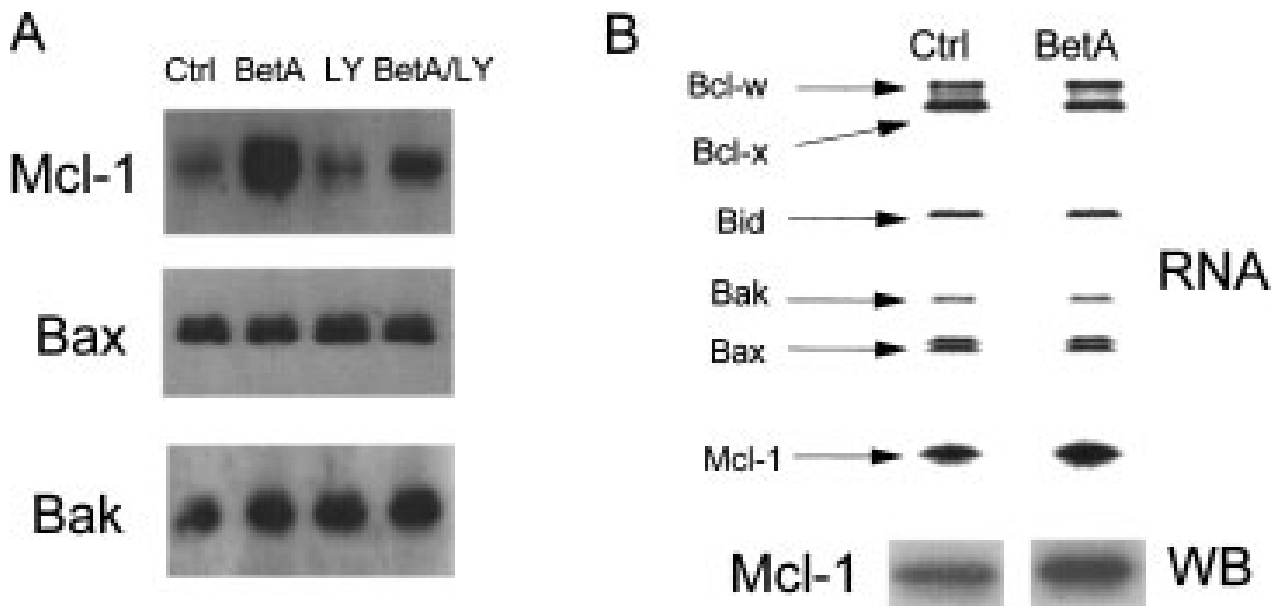

Fig. 1. Effects of betulinic acid on the expression of Mcl-1 and on various Bcl-2 family members at the protein and RNA level. (A) The melanoma cell line M20 was either untreated (Ctrl), treated with betulinic acid (BetA), with LY294002, or with both substances at concentrations of $10 \mu \mathrm{g} / \mathrm{ml}$ each for $8 \mathrm{~h}$. Western blot analysis of the expression of Bax and Bak. $10 \mu \mathrm{g}$ total protein lysate per lane was loaded. (B) RNase protection analysis of $\mathrm{Bcl}-2$ family members in untreated or betulinic acid treated $(10 \mu \mathrm{g} / \mathrm{ml})$ melanoma cells. Lower panel: concomitantly performed Mcl-1 Western blot analysis (WB) of an aliquot from the same cellular lysate. 
of other Bcl-2 family members largely remained unaltered. Densitometric scanning analysis 24 hours after addition of betulinic acid of Bax, Bak, Bad and $\mathrm{Bcl}-\mathrm{x}$ protein levels measured in five different melanoma cell lines did not show statistical significant or consistent changes $(n=3$ for each cell line, negative data not shown). We next measured expression of various Bcl-2 family members at the RNA level using a multi-probe RNase protection analysis system. Experiments were performed with 4 different cell lines in the presence or absence of betulinic acid. The results did not show significant changes in any of the Bcl-2 family members investigated other than Mcl-1. One representative RNase protection experiment is shown in Figure 1B. Mcl-1 levels were stimulated at the RNA level by $55 \%$ and at the protein level by $60 \%$ (Fig.1B, lower panel). Additional Bcl-2 family members identified in this assay are Bcl-w, Bcl-x, Bid, Bak and Bax. In contrast to the other Bcl-2 members, Bcl-w and Bid were only investigated at the RNA level. It is of interest to note in this context that this might be the first report of Bcl-w expression, a pro-apoptotic protein, in human melanoma cells. A dose-response analysis for varying concentrations of LY294002 in the presence of a fixed concentration of betulinic acid is shown in Figure 2A. Taken together, these data indicate that upregulation of Mcl-1 by betulinic acid is mediated by a LY294002 and wortm sannin-sensitive pathway (Fig. 2B).
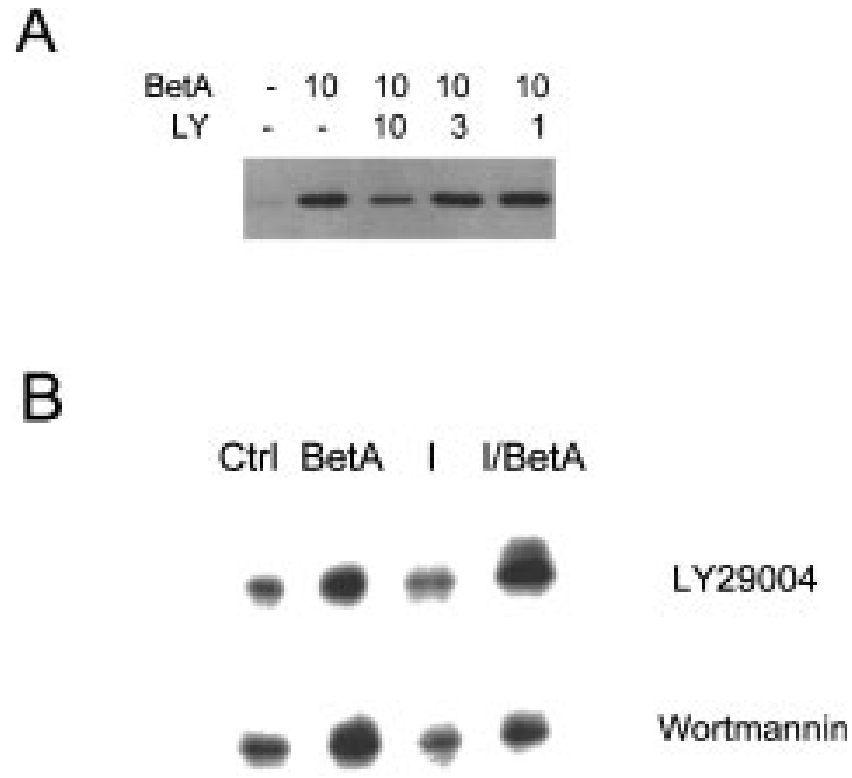

Fig. 2. Analysis of Mcl-1 expression in wortmannin, LY29004 and betulinic acid-treated cells. (A) Dose-response relationship for the inhibition of betulinic acid-induced Mcl-1 expression by LY294002. Betulinic acid (BetA) was added at fixed concentrations $(10 \mu \mathrm{g} / \mathrm{ml}) 60 \mathrm{~min}$ following addition of the indicated concentrations of LY294002 $(0,1,3$ and $10 \mu \mathrm{g} / \mathrm{ml}$, respectively). (B) Mcl-1 expression after $18 \mathrm{~h}$ incubation in the absence and presence of betulinic acid $(10 \mu \mathrm{g} / \mathrm{ml})$ and the inhibitors (I) LY294002 or wortmannin. LY29004 was added at $10 \mu \mathrm{g} / \mathrm{ml}$ final concentration and wortmannin up to a final concentration of $100 \mathrm{nM}$.

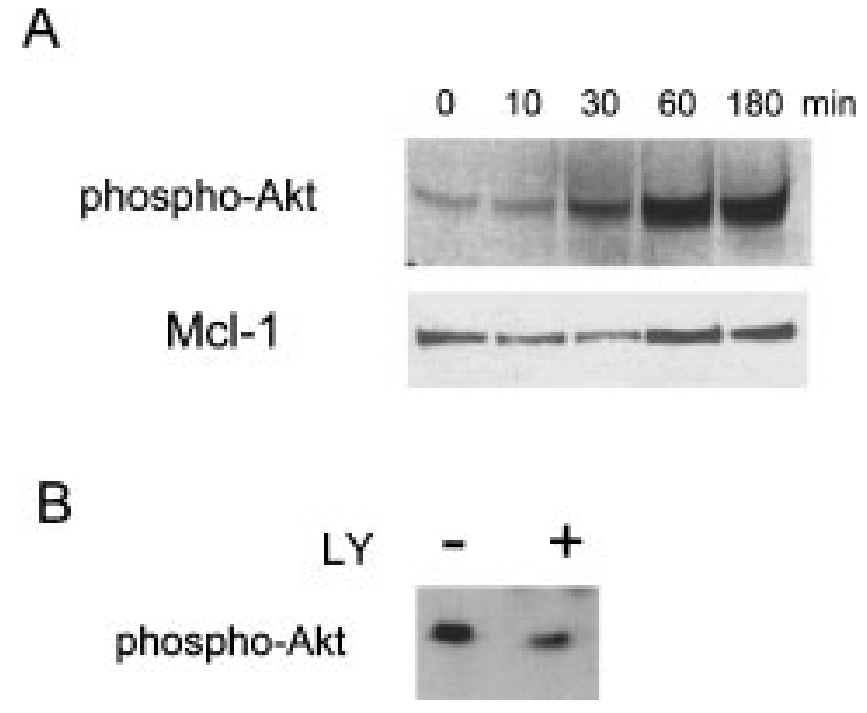

Fig. 3. Analysis of phospho-Akt and Mcl-1 expression. (A) Concomitant immunoblot analysis of phospho-Akt and Mcl-1 protein expression at the time points indicated in betulinic acid $(10 \mu \mathrm{g} / \mathrm{ml})$ treated cells. (B) Phospho-Akt levels after $18 \mathrm{~h}$ in LY29004 treated (+) and in untreated $(-)$ cells.

If true, an activation of protein kinase B (Akt), a proto-oncogenic Ser/Thr-directed protein kinase (20), which is a target of the activated PI3-kinase (12), should be a likely consequence. The relevant experiment in which the phosphorylation status of Akt in the presence of betulinic acid is analyzed is shown in Figure 3A. The time course analysis of phosphorylation indicates that Akt becomes phosphorylated after 10 to 30 minutes in betulinic acidtreated cells. A concomitantly performed analysis of Mcl-1 expression demonstrates that upregulation of this protein is slightly delayed, which is compatible with the idea that Akt-phosphorylation may be a functional prerequisite for Mcl-1 induction. LY29004 is capable of inhibiting betulinic acidinduced Akt phosphorylation (Fig. 3B).

\section{Functional Significance of Betulinic Acid-induced Akt Phosphorylation}

Akt phosphorylation alone may not suffice to prove that the enzyme is indeed activated. Further evidence for the functional significance of betulinic acid-induced Akt phosphorylation is provided by showing that phosphorylation of one of its specific substrates, glycogen synthetase kinase (21) is enhanced after treating cells with betulinic acid. GSK$3 \beta$ is a kinase expressed in melanomas and believed to be responsible for phosphorylation of $\beta$-catenin (22) and of the microphthalmia transcription factor MITF (23), two proteins that may have essential roles in melanocyte biology. Phosphorylation of GSK by immunoprecipitated Akt from betulinic acid-treated melanoma cell lysates was analyzed by Western blot using a phospho-GSK-3 specific 


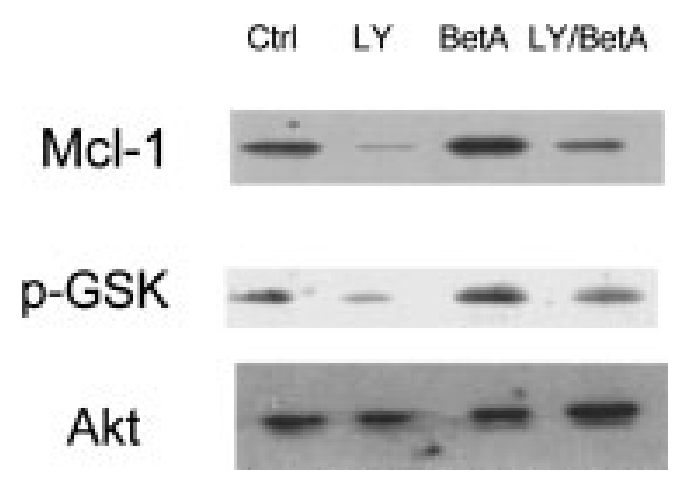

Fig. 4. Analysis of Mcl-1, p-GSK and Akt activity in betulinic acid-treated cells. Concomitant Mcl-1, phosphoGSK (p-GSK) and total (phosphorylation - state independent) Akt analysis in cells treated for $18 \mathrm{~h}$ with betulinic acid and/or LY29004 (each at $10 \mu \mathrm{g} / \mathrm{ml}$ ).

antibody (Fig. 4). Analysis of the expression of the non-phosphorylated form of Akt protein in the presence and absence of betulinic acid or LY294002 is shown in Figure 4. Phosphorylation of glycogen synthetase kinase as well as induction of Mcl-1 is inhibited by LY29004 and this effect is partially antagonized by betulinic acid in the same cells. Total Akt protein levels were not affected by betulinic acid treatment and are shown in conjunction with the respective phosphorylation experiment.

\section{Effects of Betulinic Acid on Mcl-1 Expression in the Presence of PD98059}

As mentioned above, the involvement of the MAPK pathway in non-melanoma cell lines in the regulation of Mcl-1 has been studied in quite some detail. In order to investigate the effects of an inhibition of this pathway on Mcl-1 expression in melanoma cells, we performed experiments with the welldescribed inhibitor of MEK, PD98059. Addition of PD98059 to melanoma cells led to a significant reduction of the expression of Mcl-1 and this effect was almost completely antagonized by $10 \mu \mathrm{g} / \mathrm{ml}$ betulinic acid added $60 \mathrm{~min}$ after PD98059 $(10 \mu \mathrm{g} / \mathrm{ml})$ to the cell culture medium (Fig. 5A).

In order to further investigate effects of betulinic acid on the activation pattern of the MEK1/2 and MAP-Kinase system, we used antibodies directed against the phosphorylated (activated) forms of MEK $1 / 2$ and the phosphorylated isoforms (pp42 and pp44) of MAP-Kinase (Fig. 5B). For this experiment, a vector transfected melanoma cell line 518neo and, as a positive control for MAPK activation, a mutated $\mathrm{N}$-ras transfected cell line $(518 \mathrm{Ll})$ were used. The blot was probed simultaneously with phospho-p44/42-MAPK and phospho-MEK 1/2 antibodies. This experiments demonstrates that even after 36 hours of starvation in serum free medium no influence of betulinic acid treatment on phosphoMAPK or phospho-MEK levels was found after 6 hours incubation with betulinic acid, the time
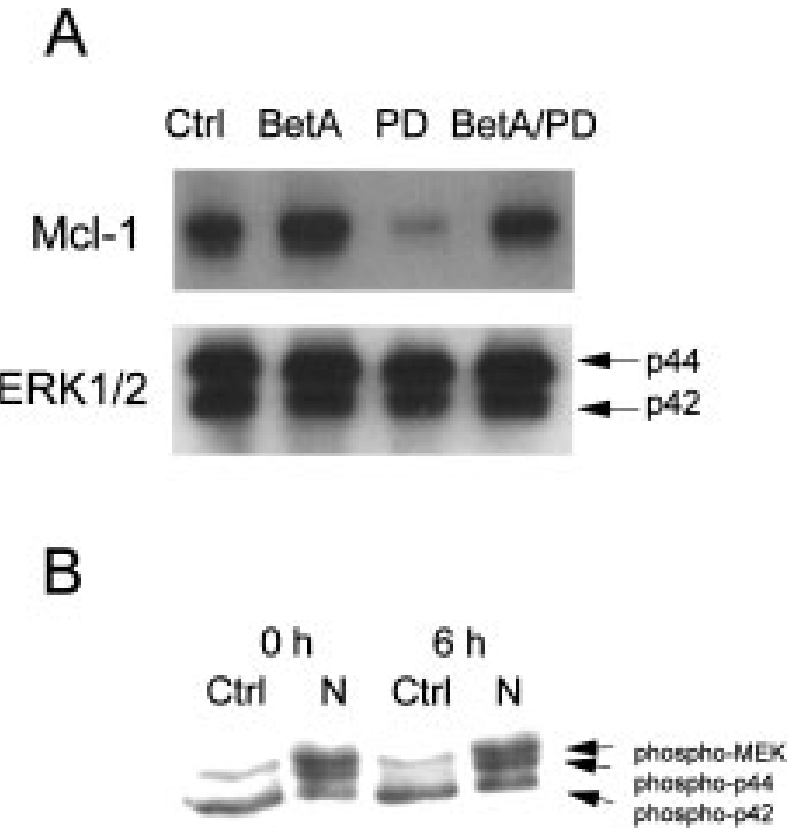

Fig. 5. Analysis of the MAPK-pathway in betulinic acidtreated cells. (A) Upper panel: Effect of PD98059 $(10 \mu \mathrm{g} / \mathrm{ml})$ on Mcl-1 expression in the presence or absence of betulinic acid $(10 \mu \mathrm{g} / \mathrm{ml})$ measured after $18 \mathrm{~h}$. Lower panel: immunoblot analysis of the same total cellular lysates with an antibody specific for ERK 1 and -2 . Arrows indicate the positions of the 42 and $44 \mathrm{kDa}$ isoforms. (B) Simultaneous phospho-MEK1/2 and phospho-MAPK analysis of a vector control (Ctrl) and activated mutant $\mathrm{N}$-ras $(\mathrm{N})$ transfected melanoma cell line (518A2). Analysis was performed after $36 \mathrm{~h}$ serum starvation of cells. After starvation, $10 \mu \mathrm{g} / \mathrm{ml}$ betulinic acid was added for the indicated times (0 and $6 \mathrm{~h}$ incubation). Arrows identify individual protein bands.

course during which activation and phosphorylation of Akt and upregulation of Mcl-1 take place.

\section{Mcl-1 Expression Levels in Melanoma are Subject to Variations due to Cell Culture Conditions}

We have already noted that basal Mcl-1 levels are subject to variations even under normal cell culture conditions (1). Since we observed that the degree of betulinic acid-induced cell death as well as the range of Mcl-1 induction was subject to poorly understood variations, we performed additional experiments. If cells are maintained for 36 hours in the presence of $0.1 \%$ serum, Mcl-1 protein expression levels are reduced compared to cells grown in the presence of $10 \%$ serum (Fig. 6A, upper panel). During this time course, melanoma cells continue to proliferate even in the presence of $0.1 \%$ serum. We found that cell density affects Mcl-1 levels (Fig. 6B). Basal Mcl-1 levels are lower in sub-confluent cell cultures compared to confluent cell cultures. In both confluent and sub-confluent cell cultures a steady decline of Mcl-1 levels in the untreated cell cultures is observed if the culture medium remains unchanged. Addition of betulinic acid at the beginning of the experiment counteracts the decline of Mcl-1 levels in 
A

\section{Serum $10 \% \quad 0.1 \%$}

B

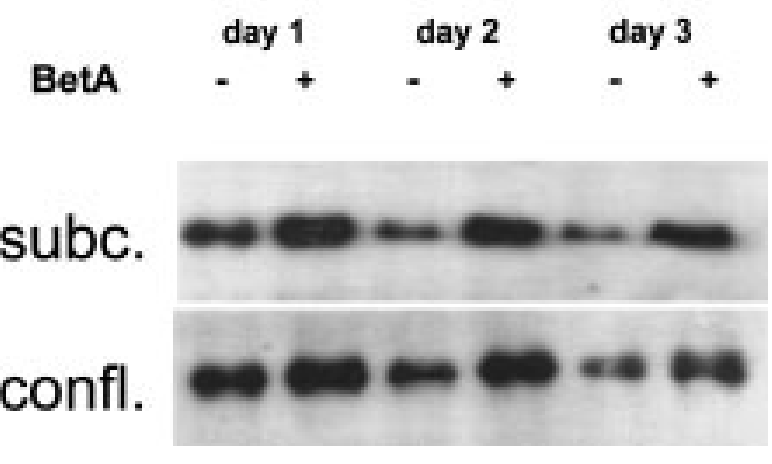

Fig. 6. Analysis of Mcl-1 expression under different cell culture conditions. (A) Immunoblot analysis of Mcl-1 expression after $36 \mathrm{~h}$ incubation in the presence of $0.1 \%$ or $10 \%$ serum. (B) Betulinic acid stimulated Mcl-1 expression in under different cell culture conditions in the presence of $10 \%$ serum. Determination of protein levels was performed 1,2 and 3 days after addition of betulinic acid $(+)$ or in untreated controls $(-)$ to either confluent (confl.) or to subconfluent (subc.) cell cultures. Cell culture medium was not changed during the course of the experiment.

both confluent and sub-confluent cultures. Induction of Mcl-1 is stronger if betulinic acid is given to non-confluent cultures compared to confluent cell cultures. Taken together, these experiments indicate that cell culture conditions, such as cell density and serum concentration modulate the expression of basal Mcl-1 levels, and this may explain variations in the efficiency of Mcl-1 induction and induced cell death by betulinic acid. It is therefore necessary, while investigating Mcl-1 effects, to keep cell culture conditions as reproducible and constant as possible. It is of interest to note that the same applies for the Mcl-1 ASO experiments presented below (unpublished observations).

\section{Functional Significance of Mcl-1 in Melanoma Cells}

Finally, the question arises whether the induction of Mcl- 1 and Mcl- 1 itself might be of biological relevance in our system. In order to address this issue we used an antisense strategy employing specific oligodeoxynucleotides targeted against $\mathrm{Mcl}-\mathrm{l}$ in melanoma cells. Figure 7A clearly displays the efficiency of downregulation of Mcl-1 in melanoma cells at the protein level after overnight treatment. Figure 7B demonstrates the effects (which are presented as the surviving fraction of untreated controls) of treating melanoma cells with either Mcl-1 antisense oligodeoxynucleotides alone (surviving fraction $=0.78 \pm 0.06(\mathrm{SD}))$, with betulinic acid alone (surviving fraction $=0.74 \pm 0.016(\mathrm{SD})$ ) and in combination with each other (surviving fraction $=0.28 \pm 0.05(\mathrm{SD}))$. The concentrations used for betulinic acid and for the Mcl-1 antisense oligonucleotide were below the half-maximal dose with respect to their growth inhibitory potency. Detailed betulinic acid growth data for various cell lines were published recently (1). Analysis of survival data indicates that a combination of both treatments is supra-additive and the differences between the surviving fractions of control-treated cells, and betulinic

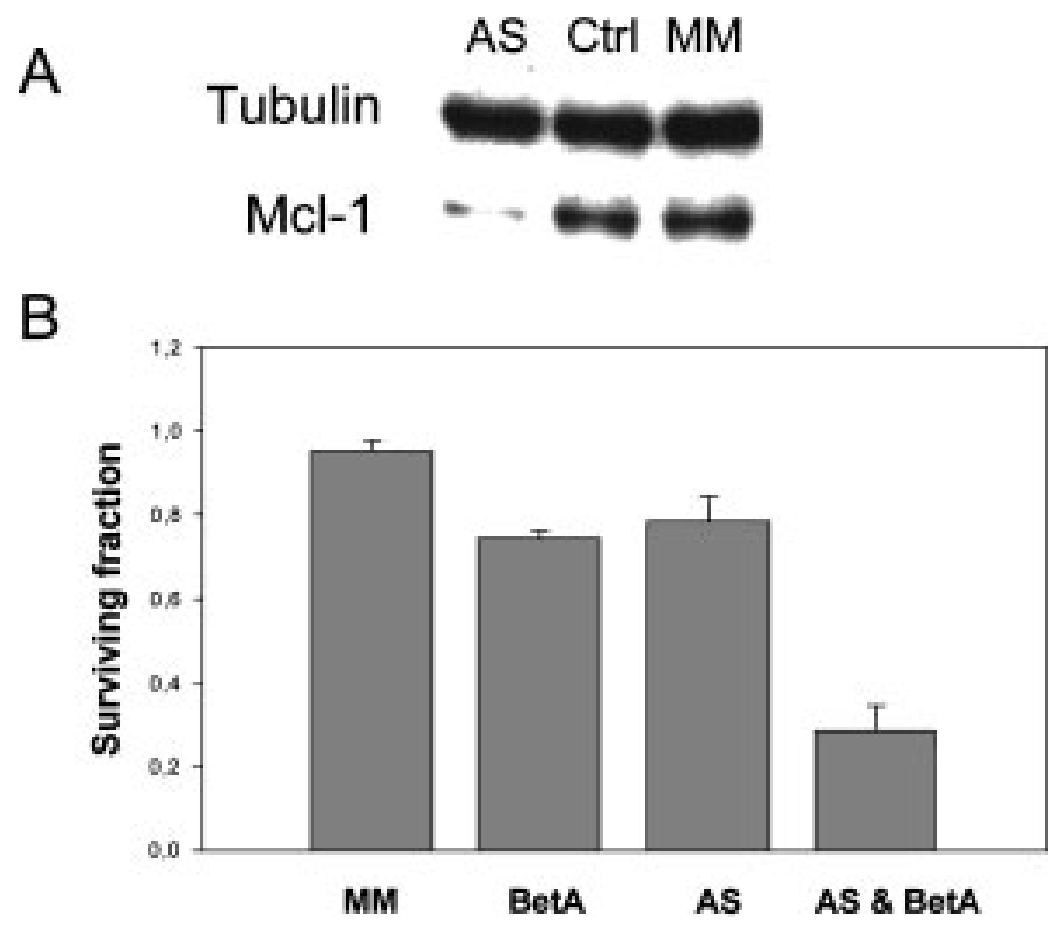

Fig. 7. Analysis of Mcl-1 expression and growth in antisense oligonucleotide-treated melanoma cells. (A) Western blot analysis of Mcl-1 expression in antisense-treated cells (AS), in untreated control cells (Ctrl), and in mismatchtreated cells (MM). In order to demonstrate equal loading, the blot was simultaneously hybridized with an antibody against alpha-tubulin. (B) Growth of betulinic acid (BetA), antisense (AS) and mismatch (MM) treated melanoma cells (melanoma cell line 518A2). Data are given as surviving fraction of untreated control cells. Cell numbers were counted after $16 \mathrm{~h}$ of treatment. Data are means of three independent experiments. Bars indicate standard deviations (SD). Final concentrations of antisense oligodeoxynucleotides in the experiments were $80 \mathrm{nM}$ and the concentration of betulinic acid was $2,5 \mu \mathrm{g} / \mathrm{ml}$. 
acid-, antisense- and betulinic acid plus antisensetreated cells were all highly significant $(P<0.005)$.

\section{Discussion}

The primary purpose of this study was to identify the molecular mechanisms by which betulinic acid, a putative selective and novel agent for cancer therapy, is capable of inducing the expression of Mcl-1 in human melanoma cells. Mcl-1, a well-known Bcl2 family member, was originally described as a gene induced during differentiation of leukaemia cells (24), but in contrast to Bcl-2, no information about the regulation of Mcl- 1 expression and/or the function of Mcl-1 in human melanoma cells was available. In this work we present results that point out for the first time that the expression of Mcl-1 can be modified in human melanoma cells through both a LY29004/wortmannin sensitive pathway and by a MAP-kinase sensitive pathway, as well as through variations of cell culture conditions, such as cell density and serum concentration.

We show that betulinic acid-induced upregulation of Mcl-l is associated with an activation of the Akt/PKB pathway. Akt phosphorylation precedes the upregulation of Mcl-1 in human melanoma cells. Incubation of melanoma cells with the MEK 1/2 inhibitor PD98059 reduced expression levels of Mcl-1. Inhibition of Mcl-1 expression by PD98059 could be antagonized by betulinic acid, indicating that the PI3-kinase and MAPK pathways are functionally interacting. Betulinic acid itself does not seem to act via the MAPK pathway to regulate Mcl-1 under the conditions tested since MAPK-phosphorylation status was unaffected by betulinic acid during the time course tested.

Betulinic acid-induced Mcl-1 expression was observed in various sarcoma cell lines as well as in a human mast cell line, indicating that this phenomenon is not restricted to melanoma cells. It is not fully understood why betulinic acid induces cell death in human melanoma cells on one hand, and on the other, upregulates the expression of an antiapoptotic protein that may in part counteract its own effect. It should be noted that betulinic acid-induced apoptosis is a late event $(3,7)$ leading to cell death 24-48 h after treatment of the cells with betulinic acid, while expression of Mcl-1 is induced during the first hours. Possibly the most direct evidence for a role of Mcl-1 in survival of melanoma cells is provided by our Mcl-1 antisense data, which show that enforced downregulation of this protein alone and in combination with betulinic acid affects survival. The effect of the compounds was synergistic, suggesting using both agents as a single strategy, or in combination with chemotherapy.

$\mathrm{PKB} /$ Akt usually is regarded as a protein that provides a survival signal protecting cells from apoptosis $(13,14)$. Recently presented data indicate that staurosporine and etoposide are capable of activating PI3K/Akt (25). Both substances function, similarly to betulinic acid (7), as mitochondrial apoptosis inducing agents. Therefore, our observation that an apoptosis-inducing agent activates Akt is not unique to betulinic acid. It is conceivable that betulinic acid may induce cell death through another - still unidentified - pathway. Induction of Mcl-1 as an early response to DNA damage in cells that undergo an apoptotic response has been demonstrated (26). Strategies to downregulate the expression of Mcl-1 may further enhance the therapeutic potential of betulinic acid as a promising and new anti-melanoma drug. In addition to enhancing the effects of betulinic acid, downregulation of Mcl-1 may be used in combination with chemotherapy to augment the therapeutic effect. A comparable approach by our group has recently led to a phase I/II clinical study in which a combination of antisense Bcl-2 oligonucleotides and systemic dacarbazine has been successfully employed in patients with metastatic melanoma (27).

\section{Acknowledgments}

We thank R. Haslinger for technical assistance. The work in B.J.`s laboratory was supported by grants from: Austrian Science Fund (FWF), Austrian National Bank, "Kommission Onkologie", "Kamillo Eisner Stiftung", "Hirtl-Buss Stiftung", "Hans and Blanca Moser Stiftung", "Anton Dreher Stiftung", "Hygienefonds", "Virologiefonds".

The work in E.S.`s Laboratory was supported by a "Fonds des Wiener Bürgermeisters" (grant no. 1690).

\section{References}

1. Selzer E, Pimentel E, Wacheck V, et al. (2000) Effects of betulinic acid alone and in combination with irradiation in human melanoma cells. J. Invest. Dermatol. 114: 935-940.

2. Selzer E, Schlagbauer-Wadl H, Okamoto I, et al. (1998) Expression of Bcl-2 family members in human melanocytes, in melanoma metastases and in melanoma cell lines. Melanoma Res. 8: 197-203.

3. Pisha E, Chai H, Lee IS, et al. (1995) Discovery of Betulinic acid as a selective inhibitor of human melanoma that functions by induction of apoptosis. Nat. Med. 1: 1046-1051.

4. Schmidt ML, Kuzmanoff KL, Ling-Indeck L, Pezzuto JM. (1997) Betulinic acid induces apoptosis in human neuroblastoma cell lines. Eur. J. Cancer. 33: 2007-2010.

5. Rieber M, Strasberg-Rieber M. (1998) Induction of p53 without increase in p2lWAF1 in Betulinic acid-mediated cell death is preferential for human metastatic melanoma. DNA. Cell. Biol. 17: 399-406.

6. Fulda S, Friesen C, Los M, et al. (1997) Betulinic acid triggers CD95 (APO-1/Fas)- and p53-independent apoptosis via activation of caspases in neuroectodermal tumors. Cancer Res. 57: 4956-4964.

7. Fulda S, Scaffidi C, Susin SA, et al. (1998) Activation of mitochondria and release of mitochondrial apoptogenic factors by Betulinic acid. J. Biol. Chem. 273: 33942-33948.

8. Fulda S, Jeremias I, Steiner HH, et al. (1999) Betulinic acid: a new cytotoxic agent against malignant brain-tumor cells. Int. J. Cancer. 82: 435-441.

9. Chao JR, Wang JM, Lee SF, et al. (1998) Mcl-1 is an immediate-early gene activated by the granulocyte-macrophage colony-stimulating factor (GM-CSF) signaling pathway and 
is one component of the GM-CSF viability response. Mol. Cell. Biol. 18: 4883-4898.

10. Wang JM, Chao JR, Chen W, et al. (1999) The antiapoptotic gene mcl-l is up-regulated by the phosphatidylinositol 3-kinase/Akt signaling pathway through a transcription factor complex containing CREB. Mol. Cell. Biol. 19: 6195- 6206.

11. Klein JB, Rane MJ, Scherzer JA, et al. (2000) Granulocytemacrophage colony-stimulating factor delays neutrophil constitutive apoptosis through phosphoinositide 3-kinase and extracellular signal-regulated kinase pathways. J. Immunol. 164: 4286-4291.

12. Franke TF, Yang SI, Chan TO, et al. (1995) The protein kinase encoded by the Akt proto-oncogene is a target of the PDGFactivated phosphatidylinositol 3-kinase. Cell. 2: 727-736.

13. Hemmings BA. (1997) Akt signaling: linking membrane events to life and death decisions. Science. 275: 628-630.

14. Marte BM, Downward J. (1997) PKB/Akt: connecting phosphoinositide 3-kinase to cell survival and beyond. Trends Biochem. Sci. 22: 355-358.

15. Townsend KJ, Trusty JL, Traupman MA, et al. (1998) Expression of the antiapoptotic MCLl gene product is regulated by a mitogen activated protein kinase-mediated pathway triggered through microtubule disruption and protein kinase C. Oncogene. 10: 1223-1234.

16. Stambolic V, Mak TW, Woodgett JR. (1999) Modulation of cellular apoptotic potential: contributions to oncogenesis. Oncogene. 1: 6094-6103.

17. Huang HM, Huang CJ, Yen JJ. (2000) Mcl-1 is a common target of stem cell factor and interleukin-5 for apoptosis prevention activity via MEK/MAPK and PI-3K/Akt pathways. Blood. 96: 1764-1771.

18. Kuo ML, Chuang SE, Lin MT, Yang SY. (2001) The involvement of PI 3-K/Akt-dependent up-regulation of Mcl-1 in the prevention of apoptosis of Hep3B cells by interleukin-6. Oncogene. 20: 677-85.

19. Jansen B, Schlagbauer-Wadl H, Eichler HG, et al. (1997) Activated $\mathrm{N}$-ras contributes to the chemoresistance of human melanoma in severe combined immunodeficiency (SCID) mice by blocking apoptosis. Cancer Res. 57: 362-365.

20. Toker A, Cantley LC. (1997) Signalling through the lipid products of phosphoinositide-3-OH kinase. Nature. 387: 673676.

21. Van Weeren PC, de Bruyn KM, de Vries-Smits AM, et al. (1998) Essential role for protein kinase B (PKB) in insulininduced glycogen synthase kinase 3 inactivation. Characterization of dominant-negative mutant of PKB. J. Biol. Chem. 273: 13150-13156.

22. Rubinfeld B, Robbins P, El-Gamil M, et al. (1997) Stabilization of beta-catenin by genetic defects in melanoma cell lines. Science. 275: 1790-1792.

23. Takeda K, Takemoto C, Kobayashi I, et al. (2000) Ser298 of MITF, a mutation site in Waardenburg syndrome type 2, is a phosphorylation site with functional significance. Hum Mol Genet. 1: 125-132.

24. Kozopas KM, Yang T, Buchan HL, et al. (1993) MCLl, a gene expressed in programmed myeloid cell differentiation, has sequence similarity to BCL2. Proc. Natl. Acad. Sci. USA. 90: 3516-3520.

25. Tang D, Okada H, Ruland J, et al. (2001) Akt is activated in response to an apoptotic signal. J. Biol. Chem. 10: 30461-30466.

26. Zhan Q, Bieszczad CK, Bae I, et al (1997) Induction of BCL2 family member MCLl as an early response to DNA damage. Oncogene. 6: 1031-1039.

27. Jansen B, Wacheck V, Heere-Ress E, et al. (2000) Chemosensitisation of malignant melanoma by BCL2 antisense therapy. Lancet. 18: 1728-1733. 